\title{
Between Warrior Brother and Veiled Sister. Islamic Fundamentalism and the Politics of Patriarchy in Iran. Berkely - Los Angeles - London, University of California Press, 2005, 269 p.
}

\section{Azadeh Kian-Thiébaut}

\section{(2) OpenEdition}

\section{Journals}

Édition électronique

URL : http://journals.openedition.org/abstractairanica/20361

DOI : 10.4000/abstractairanica.20361

ISSN : 1961-960X

Éditeur :

CNRS (UMR 7528 Mondes iraniens et indiens), Éditions de l'IFRI

Édition imprimée

Date de publication : 15 mai 2007

ISSN : 0240-8910

\section{Référence électronique}

Azadeh Kian-Thiébaut, « Between Warrior Brother and Veiled Sister. Islamic Fundamentalism and the Politics of Patriarchy in Iran. Berkely - Los Angeles - London, University of California Press, 2005, 269 p. », Abstracta Iranica [En ligne], Volume 28 | 2007, document 402, mis en ligne le 18 septembre 2007, consulté le 25 septembre 2020. URL : http://journals.openedition.org/abstractairanica/20361 ; DOI : https://doi.org/10.4000/abstractairanica.20361

Ce document a été généré automatiquement le 25 septembre 2020.

Tous droits réservés 


\title{
Between Warrior Brother and Veiled Sister. Islamic
} Fundamentalism and the Politics of Patriarchy in Iran. Berkely - Los Angeles - London, University of California Press, 2005, 269 p.

\author{
Azadeh Kian-Thiébaut
}

1 Dans une perspective post-moderne et féministe transnationale, l'A. analyse le chevauchement $\mathrm{du}$ genre et $\mathrm{du}$ fondamentalisme en Iran et considère le fondamentalisme islamique comme un produit de la modernité coloniale et du processus de modernisation et d'occidentalisation. Le fondamentalisme islamique est donc indicateur d'une crise de la modernité, de la rationalité et de genre plutôt que de la tradition. L'ouvrage est fondé sur des sources secondaires, textuelles et visuelles, notamment de films iraniens. A travers une lecture critique de quelques récits de voyages d'Européens, l'A. montre que ceux-ci qualifiaient la Perse du XIX ${ }^{e}$ s. d'absolutiste et de barbare afin de légitimer l'intervention européenne en Iran. Pour M. Moallem, la construction de la nation iranienne ne peut être séparée de la construction de la personnalité persane par les voyageurs, les missionnaires ou les officiers. Cette personnalité persane ayant besoin de la civilisation est aussi présente dans les écrits des élites modernisatrices. L'A. montre que dans le discours occidental, la condition des femmes sert à définir les frontières entre le monde "civilisé » de l'Europe et le monde «barbare» de l'islam. L'image raciste et colonialiste des femmes musulmanes comme éternelles victimes, caractérisées par l'ignorance et la passivité, est devenue le cliché le plus rassurant pour les Occidentaux. Se fondant sur l'analyse de Michel Foucault, l'A. compare ensuite les discours sur l'Iran avant et après la révolution ; il affirme que ces discours ont créé de nouveaux sujets féminisés et leur ont demandé d'assurer l'hétérosexualité. Le but était le contrôle disciplinaire du corps et la 
création sexuée de la citoyenneté nationale et internationale. L'A. affirme que la révolution iranienne a défié les discours de la modernité en dépassant la division entre la pensée d'une part, l'émotion et le corps d'autre part. La révolution a aussi défié l'ordre culturel de la modernité en intégrant les cultures populaire et savante et en mettant en question la dichotomie entre le religieux et le laïque. A travers une analyse originale, M.M. montre que le martyre comme processus de remasculinisation a intégré le langage symbolique de l'identité sexuée. Les femmes entrent dans la sphère du martyre exclusivement comme membres de la famille. Le port du voile devient une part importante de cette domestication, racialisation et sexualisation de l'idéologie fondamentaliste. Néanmoins, les femmes ont accepté le voile non comme un signe de passivité ou de religiosité, mais plutôt comme une invitation sexuée de participation politique et comme un signe d'appartenance et de complicité. A travers une discussion brève du féminisme islamique en Iran, l'A. affirme que le féminisme et le fondamentalisme ont créé des hybrides, à savoir un féminisme avec des éléments fondamentalistes et un fondamentalisme avec des éléments féministes.

INDEX

Thèmes : 12.1. Iran

\section{AUTEURS}

\section{AZADEH KIAN-THIÉBAUT}

Université Paris VIII / Mondes iranien et indien 